\title{
EFEKTIVITAS KOMPRES AIR HANGAT DAN AIR DINGIN TERHADAP PENURUNAN INTENSITAS NYERI PADA REMAJA PUTRI DENGAN DISMENORE
}

\author{
Amrina Rosyada Amalia ${ }^{1 凶}$, Yulia Susanti ${ }^{2}$, Dwi Haryanti ${ }^{2}$ \\ ${ }^{1}$ Mahasiswa Program Studi Ilmu Keperawatan STIKES Kendal \\ ${ }^{2}$ Dosen Program Studi Ilmu Keperawatan STIKES Kendal
}

\section{ARTICLE INFO \\ Article history \\ Submitted : 2020-01-24 \\ Revised : 2020-01-25 \\ Accepted : 2020-01-29}

\section{Keywords: \\ Warm water compress Cold water compress Pain intensity \\ Dysmenorrhea} \begin{abstract}
Dysmenorrhea is pain during or before the start of menstruation. The incidence of dysminorrhea in adolescents in Central Java by 2015 is estimated to be $12 \%$ to $35 \%$ of teenagers, while in Kendal regency as many as 11,565 people $(29.8 \%)$. Methods of hot and cold water compress ispart of the non-pharmacological methods that are effective, easy, and cheap to overcome dysmenorrheal pain. The purpose of this research was to know the difference of warm water compress and cold water compress to decrease pain intensity of adolescent girl with dysmenorrhea. This research usei Quasi Experimental design with Pretest-Posttest design, Non-Equivalent Control Group Design. The sample in this study amounted to 34 people, in each treatment group of 17 people whith was collected with the reasareh uset questeonnare bowbonais as researeh instrument pair schale.the consecutive sampling. Data analysis used Wilcoxonand Man Withn. The results showed that there was a difference in pain intensity before and after being given warm water compresses in adolescent girls with dysmenorrhea ( $p$ value $0.000<0.05$ ). There was a difference in pain intensity before and after being given cold water compresses on adolescent girls with dysmenorrhea ( $\mathrm{p}$ value $0.000<0.05$ ). Warm water compresses are more effective at reducing the intensity of pain than cold water compresses in adolescent girl with dysmenorrhea. It is expected that adolescent girls who experience dysmenorrhea can use warm compress cold water compress therapy independently when experiencing dysmenorrhea pain that can reduce the consumption of painkillers.

Dismenore merupakan nyeri selama atau sesaat sebelum menstruasi. Angka kejadian disminore pada remaja putri di Jawa Tengah tahun 2015 diperkirakan 12\% sampai 35\% dari jumlah remaja, sementara di Kabupaten Kendal sebanyak 11.565 jiwa $(29,8 \%)$. Metode kompres air panas dan dingin merupakan bagian dari metode non farmakologi yang efektif, mudah, dan murah untuk mengatasi nyeri dismenore. Tujuan penelitian ini untuk mengetahui perbedaan kompres air hangat dan kompres air dingin terhadap penurunan intensitas nyeri pada remaja putri dengan dismenore. Penelitian ini menggunakan desain Quasi Eksperimental dengan rancangan Pretest-Posttest, NonEquivalent Control Group Design. Sampel dalam penelitian ini berjumlah 34 orang, pada masing-masing kelompok perlakuan 17 orang dengan teknik consecutive sampling. Penelitian ini menggunakan kuesioner skala nyeri dari bourbonais sebagai alat ukur penelitian. Analisa data menggunakan uji Wilcoxon dan uji Man Withney. Hasil penelitian menunjukkan bahwa terdapat perbedaan intensitas nyeri sebelum dan sesudah diberi kompres air hangat pada remaja putri dengan dismenore ( $\mathrm{p}$ value $0.000<$ 0.05). Terdapat perbedaan intensitas nyeri sebelum dan sesudah diberi kompres air dingin pada remaja putri dengan dismenore ( $\mathrm{p}$ value $0.000<0.05$ ). Kompres air hangat lebih efektif dalam menurunkan intensitas nyeri daripada kompres air dingin pada remaja putri dengan dismenore. Diharapkan remaja putri yang mengalami dismenore dapat menggunakan terapi kompres air hangat kompres air dingin secara mandiri saat mengalami nyeri dismenore sehingga dapat mengurangi konsumsi obat-obatan penghilang nyeri.
\end{abstract}

$\triangle$ Corresponding Author:

Amrina Rosyada Amalia

Mahasiswa Program Studi Ilmu Keperawatan STIKES Kendal

Telp. 082137919011

Email: Amrinarosyada_amalia@yahoo.com 


\section{PENDAHULUAN}

Dismenore merupakan nyeri selama atau segera sebelum menstruasi menjadi salah satu masalah ginekologik yang paling umum terjadi pada wanita dari segala usia (Lowdermilk, 2010). Nyeri haid merupakan penyakit yang sudah lama dikenal. Nyeri yang dirasakan tidak hanya terjadi pada bagian perut bawah saja. Beberapa remaja perempuan sering merasakan pada punggung bagian bawah, pinggang, panggul, otot paha atas, hingga betis. Rasa nyeri dapat disebabkan oleh kontraksi otot perut yang terjadi secara terus menerus saat mengeluarkan darah (Laila, 2011). Diperkirakan sekitar 50\% dari seluruh wanita di dunia menderita akibat dismenore dalam sebuah siklus menstruasi. Angka kejadian dismenore di Indonesia sebesar $64,25 \%$ yang terdiri dari $54,89 \%$ dismenore primer dan 9,36\% dismenore sekunder (Info sehat, 2015).

Angka kejadian disminore pada remaja di Jawa Tengah tahun 2015 diperkirakan 12\% sampai 35\% dari jumlah remaja dan jumlah penderita yang memeriksakan diri ke petugas kesehatan mencapai 56\% (Dinas Kesehatan Provinsi Jawa Tengah, 2015). Jumlah remaja putri berusia $10-24$ tahun yang mengalami dismenore berdasarkan data di bagian kebidanan pada tahun 2013 sebanyak 11.565 jiwa. Remaja putri yang mengalami dismenore pada tahun 2014 sebanyak 11.570 jiwa sedangkan pada tahun 2015 yang mengalami dismenore jumlahnya yaitu 11.565 jiwa $(29,8 \%)$ (Dinas Kesehatan Kabupaten Kendal, 2015).

Dismenore dapat ditangani dengan metode farmakologi dan non farmakologi. Penanganan dismenore secara farmakologi yaitu dengan pemberian obat-obatan analgesik (Wilmana \& Gan, 2007). Secara non farmakologi manajemen nyeri lebih aman digunakan karena tidak menumbulkan efek samping seperti obat-obatan. Melalui distraksi, relaksasi, imajinasi terbimbing, kompres hangat atau dingin. Metode pemberian kompres air hangat dan dingin dapat digunakan untuk mengurangi nyeri dismenore. Metode ini menggunakan proses fisiologis tubuh (Mutaqqin, 2011).

Metode kompres air panas dan dingin merupakan salah satu metode non farmakologi yang efektif, mudah, dan murah. Namun hingga kini masih banyak wanita yang belum menggunakan penanganan tersebut dalam mengurangi dismenore. Kompres hangat itu sendiri dapat dilakukan dengan menggunakan botol kompres yang telah diisi air hangat dan dikompreskan selama 20 menit merupakan suatu terapi sederhana penghantar hangat yang bertujuan untuk mengurangi rasa nyeri, spasme, dan iskemia (Arofah, 2010). Efek hangat yang dihasilkan oleh kompres hangat dapat meredakan iskemia dengan menurunkan kontraksi uterus dan melancarkan pembuluh darah sehingga dapat meredakan nyeri dengan menurunkan ketegangan dan memberikan efek berupa rasa nyaman (Bobak, 2005).

Penelitian yang berkaitan dengan penanganan dismenore dengan kompres hangat pernah dilakukan oleh Anugraheni dan Wahyuningsih (2013); Rohmawaty dan Ekawati (2014), hasil penelitiannya menyatakan bahwa kompres hangat dapat menurunkan intensitas nyeri dismenore. Penelitian yang dilakukan oleh Hartaningsih dan Turlina (2009) menunjukkan bahwa pemberian kompres air hangat dapat mengurangi intensitas nyeri dismenore.

Pemberian kompres dingin dipercaya dapat meningkatkan pelepasan endorfin yang memblok transmisi stimulus nyeri dan juga menstimulasi serabut saraf berdiameter besar A-Beta sehingga menurunkan transmisi implus nyeri melalui serabut kecil A-delta dan serabut saraf C. Tindakan kompres dingin selain memberikan efek menurunkan sensasi nyeri, kompres dingin juga memberikan efek fisiologis seperti menurunkan respon inflamasi jaringan, menurunkan aliran darah dan mengurangi edema (Tamsuri, 2007).

Penelitian yang berkaitan dengan penanganan dismenore dengan kompres dingin pernah dilakukan oleh Anugraheni dan Wahyuningsih (2013), Rohmawaty dan Ekawati (2014), Khodijah (2011), Rizqi (2012) dan Muttaqin (2011) tentang kompres air panas dan dingin dapat mempengaruhi penurunan intensitas nyeri dismenore, maka dari itu peneliti tertarik untuk meneliti tentang keefektifan kompres air panas dan air dingin untuk menurunkan intensitas nyeri menstruasi pada remaja putri.

Berdasarkan survey pendahuluan di MAN Kendal tanggal 25 Oktober 2016 pada siswa kelas $\mathrm{X}$, wawancara yang dilakukan pada 10 siswi terdapat 7 siswi yang pernah mengalami dismenore primer. Siswi yang mengalami dismenore primer mengatakan 
untuk penanganannya 5 orang siswi mengkonsumsi obat anti nyeri dan 2 orang lainnya mengatasinya dengan beristirahat. Semua siswi mengatakan belum pernah menggunakan kompres air hangat atau kompres air dingin untuk menangani nyeri haid. Terdapat 6 orang siswi yang mengaku sampai tidak hadir di sekolah karena nyeri haid yang dirasakan. Peneliti ingin membandingkan penanganan dismenore yang lebih efektif dan efisien dari kompres hangat dan kompres dingin

Tujuan penelitian ini adalah untuk mengetahui perbedaan kompres air hangat dan kompres air dingin terhadap penurunan intensitas nyeri pada remaja putri dengan dismenore di MAN Kendal.

\section{METODE PENELITIAN}

\section{Jenis Penelitian}

Jenis penelitian yang digunakan dalam penelitian ini adalah Quasi Eksperimental dengan rancangan Pretest-Posttest, NonEquivalent Control Group Design.

\section{Lokasi dan Waktu Penelitian}

Penelitian ini berlokasi di Madrasah Aliyah Negeri Kendal. Penelitian ini dilaksanakan pada bulan September 2016 - April 2017.

\section{Populasi dan Sampel}

Populasi dalam penelitian ini adalah semua siswi kelas X di MAN Kendal yang mengalami disminore sejumlah 64 orang. Sampel dalam penelitian ini adalah siswi kelas $\mathrm{X}$ di MAN Kendal yang mengalami dismenore sejumlah 34 orang yang dibagi menjadi 2 kelompok yang masing-masing sejumlah 17 orang. Teknik sampling dalam penelitian ini adalah menggunakan consecutive sampling.

\section{Pengumpulan Data}

Pengumpulan data dilakukan dengan menggunakan kuesioner menggunakan skala nyeri berdasarkan Bourbonais dengan penggolongan nyeri skala $0=$ tidak nyeri, $1-3$ = nyeri ringan, $4-6=$ nyeri sedang, $7-9=$ nyeri berat terkontrol dan $10=$ nyeri berat tidak terkontrol.

\section{Pengolahan dan Analisa Data}

Pengolahan data skala nyeri disminorea yang dirasakan sebelum dan atau setelah dilakukan kompres air hangat atau air dingin dalam bentuk distribusi frekuensi dan tendensi sentral.

Pada penelitian ini sebelum dilakukan uji statistik pada vaiabel dependen terlebih dahulu dilakukan uji normalitas dengan menggunakan uji Shapiro wilk. Analisa bivariat menggunakan uji Wilcoxon dan uji Man Withney Test.

\section{HASIL PENELITIAN}

Intensitas Nyeri Sebelum dan Sesudah diberi Kompres Air Hangat

Tabel 1. Intensitas Nyeri Sebelum dan Sesudah diberi Kompres Air Hangat pada Remaja Putri dengan Dismenore $(n=17)$

\begin{tabular}{lcccc}
\hline \multicolumn{1}{c}{ Variabel } & Mean & $\begin{array}{c}\text { Standar } \\
\text { Deviasi }\end{array}$ & Min & Max \\
\hline $\begin{array}{l}\text { Intensitas Nyeri } \\
\text { (sebelum) } \\
\text { diberi Kompres }\end{array}$ & 4,94 & 0,827 & 4 & 6 \\
$\begin{array}{l}\text { Air Hangat } \\
\text { Intensitas Nyeri } \\
\text { (sesudah) diberi }\end{array}$ & 2,29 & 0,849 & 1 & 4 \\
$\begin{array}{l}\text { Kompres Air } \\
\text { Hangat }\end{array}$ & & & & \\
\hline
\end{tabular}

Pada tabel 1 dapat disimpulkan terjadi penurunan intensitas nyeri sebelum dan sesudah diberikan kompres air hangat.

\section{Intensitas Nyeri Sebelum dan Sesudah diberi Kompres Air Dingin}

Tabel 2. Intensitas Nyeri Sebelum dan Sesudah diberi Kompres Air Dingin pada Remaja Putri dengan Dismenore $(\mathbf{n}=\mathbf{1 7})$

\begin{tabular}{lcccc}
\hline \multicolumn{1}{c}{ Variabel } & Mean & $\begin{array}{c}\text { Standar } \\
\text { Deviasi }\end{array}$ & Min & Max \\
\hline $\begin{array}{l}\text { Intensitas Nyeri } \\
\text { (Sebelum) diberi }\end{array}$ & 5,06 & 0,748 & 4 & 6 \\
$\begin{array}{l}\text { Kompres Air } \\
\text { Dingin }\end{array}$ & & & & \\
\hline $\begin{array}{l}\text { Intensitas Nyeri } \\
\text { (Sesudah) diberi }\end{array}$ & 3,65 & 0,606 & 3 & 5 \\
$\begin{array}{l}\text { Kompres Air } \\
\text { Dingin }\end{array}$ & & & & \\
\hline
\end{tabular}


Pada tabel 2 dapat disimpulkan terjadi penurunan intensitas nyeri sebelum dan sesudah diberikan kompres air dingin.

Perbedaan Intensitas Nyeri Sebelum dan Sesudah diberi Kompres Air Hangat

Tabel 3. Perbedaan Intensitas Nyeri Sebelum dan Sesudah diberi Kompres Air Hangat pada Remaja Putri Dengan Dismenore $(\mathbf{n}=\mathbf{1 7})$

\begin{tabular}{llllll}
\hline \multicolumn{1}{c}{ Variabel } & N & Mean & STD & $\mathbf{Z}$ & p value \\
\hline $\begin{array}{l}\text { Intensitas Nyeri } \\
\text { (Sebelum) diberi }\end{array}$ & 17 & 4,94 & 0,827 & & \\
$\begin{array}{l}\text { Kompres Air } \\
\text { Hangat }\end{array}$ & & & & & \\
\hline $\begin{array}{l}\text { Intensitas Nyeri } \\
\text { (Sesudah) diberi }\end{array}$ & 17 & 2,29 & 0,849 & 0,000 \\
$\begin{array}{l}\text { Kompres Air } \\
\text { Hangat }\end{array}$ & & & & & \\
\hline
\end{tabular}

Tabel 3 menunjukkan bahwa intensitas nyeri (sebelum) diberi kompres air hangat ratarata 4,94, sedangkan intensitas nyeri (sesudah) diberi kompres air hangat rata-rata 2,29. Hasil uji Wilcoxon match pair test didapatkan nilai $\mathrm{p}$ value $=0,000(\alpha<0,05)$, maka Ho ditolak dan Ha diterima artinya ada perbedaan yang signifikanintensitas nyeri sebelum dan sesudah diberikan kompres air hangat pada remaja putri dengan dismenore.

Perbedaan Intensitas Nyeri Sebelum dan Sesudah diberi Kompres Air Dingin

Tabel 4. Perbedaan Intensitas Nyeri Sebelum dan Sesudah diberi Kompres Air Dingin pada Remaja Putri dengan Dismenore $(n=17)$

\begin{tabular}{lccccc}
\hline \multicolumn{1}{c}{ Variabel } & $\mathbf{N}$ & Mean & $\begin{array}{c}\text { Standar } \\
\text { Deviasi }\end{array}$ & $\mathbf{Z}$ & $\begin{array}{c}\mathbf{p} \\
\text { value }\end{array}$ \\
\hline $\begin{array}{l}\text { Intensitas Nyeri } \\
\text { (Sebelum) } \\
\text { diberi Kompres }\end{array}$ & 17 & 5,06 & 0,748 & & \\
$\begin{array}{l}\text { Air Dingin } \\
\text { Intensitas Nyeri }\end{array}$ & & & & & \\
$\begin{array}{l}\text { (Sesudah) diberi } \\
\text { Kompres Air }\end{array}$ & 17 & 3,65 & 0,606 & 0,000 \\
\begin{tabular}{l} 
Dingin \\
\hline
\end{tabular}
\end{tabular}

Tabel 4 menunjukkan bahwa intensitas nyeri (sebelum) diberi kompres air dingin rata- rata 5,06, sedangkan intensitas nyeri (sesudah) diberi kompres air dingin rata-rata 3,65.

Hasil uji Wilcoxon match pair test didapatkan nilai $\mathrm{p}$ value $=0,000(\alpha<0,05)$, maka Ho ditolak dan $\mathrm{Ha}$ diterima artinya ada perbedaan yang signifikan intensitas nyeri sebelum dan sesudah diberikan kompres air dingin pada remaja putri dengan dismenore.

Tabel 5. Efektivitas Kompres Air Hangat dan Kompres Air Dingin terhadap Penurunan Intensitas Nyeri pada Remaja Putri dengan Dismenore $(n=34)$

\begin{tabular}{lcccccc}
\hline \multicolumn{1}{c}{$\begin{array}{c}\text { Pemberian } \\
\text { Kompres }\end{array}$} & N & Mean & $\begin{array}{c}\text { Standar } \\
\text { Deviasi }\end{array}$ & $\mathbf{Z}$ & $\begin{array}{c}\boldsymbol{\rho} \\
\text { value }\end{array}$ \\
\hline $\begin{array}{l}\text { Penurunan } \\
\text { Intensitas }\end{array}$ & $\begin{array}{c}\text { Air } \\
\text { Hangat }\end{array}$ & 17 & 2,64705 & 1,41176 & & \\
\cline { 2 - 5 } & $\begin{array}{c}\text { Air } \\
\text { Dingin }\end{array}$ & 17 & 1,41176 & 0,5073 & & \\
\hline
\end{tabular}

Tabel 5 menunjukkan bahwa nilai rataratapenurunan intensitas nyeripada remaja putri dengan dismenore yang diberi kompres air hangat lebih tinggi $(2,64705)$ dibandingkan kompres air dingin $(1,41176)$. Berdasarkan analisis statistik menggunakan uji Mann Whitney didapatkan nilai pvalue 0,000 . Nilai $\mathrm{Z}$ hitung sebesar $-4,053$ yang merupakan nilai mutlak. Hal ini menunjukkan bahwa nilai $\rho$ value lebih kecil dari $\alpha$ value 0,05 ), sehingga Ho ditolak Ha diterima, yang berarti ada perbedaan yang signifikan antara intensitas nyeri dismenore yang diberikan kompres air hangatdan kompres air dingin pada remaja putri dengan dismenore. Hal ini menunjukkan bahwa kompres air hangat lebih efektif dalam menurunkan intensitas nyeri dismenore dibandingkan diberikan kompres air dingin

\section{PEMBAHASAN}

\section{Intensitas Nyeri Sebelum diberi Kompres Air Hangat}

Rata-rata dismenore sebelum dilakukan kompres hangat Berdasarkan hasil penelitian didapatkan data bahwa intensitas nyeri dismenore sebelum dilakukan kompres air hangat nilai terendah adalah 4 , nilai tertinggi adalah 6 dan nilai rata-rata adalah 4,94.

Sesuai data yang didapatkan dari responden rata-rata responden yang mengalami nyeri (skala 4 - 6) yang dideskriptifkan dismenore sedang. Data tersebut menunjukkan 
responden yang mengalami nyeri (dari skala 4 6) yang dideskriptifkan dismenore sedang mengatakan ketika mereka sedang mengalami dismenore mereka tidak mengonsumsi obat atau menggunakan hal yang lainnya untuk mengurangi nyeri. Alasan mereka tidak menggunakan obat-obatan karena mereka takut menimbulkan dampak ketergantungan terhadap obat-obatan.

Hasil penelitian ini menunjukkan skala intensitas nyeri dismenore responden bervariasi karena nyeri yang dirasakan individu satu dengan yang lainnya tidak sama. Sesuai yang disampaikan (Tamsuri, 2007), bahwa perbedaan nyeri ini dipengaruhi oleh beberapa faktor seperti usia, jenis kelamin, kultur/budaya, dukungan keluarga/sosial, dan koping. Kondisi tubuh seseorang yang tidak akan sama satu dengan yang lainnya yang disebabkan oleh perbedaan kadar endorphin. Endorphin berfungsi mengatur berbagai fungsi fisiologi transmisi nyeri, emosi, kontrol nafsu makan dan sekresi hormon. Perbedaan kadar endorphin yang tinggi akan sedikit merasakan nyeri dan kadar endorphin yang sedikit akan merasakan nyeri yang berlebih (Harry, 2007).

Usia remaja banyak yang mengalami dismenore yaitu sekitar $60-80 \%$ karena mereka sedang mengalami tahap pertumbuhan dan perkembangan fisik. Menurut (Harry, 2007), dismenore dapat berlebihan jika dipengaruhi oleh faktor psikis dan fisik seperti stres, syok, kurang darah, dan kondisi tubuh yang menurun.

\section{Intensitas Nyeri Sesudah diberi Kompres Air Hangat}

Rata-rata nyeri dismenore sesudah dilakukan kompres hangat Berdasarkan hasil penelitian sesudah diberikan kompres hangat didapatkan paling banyak responden dengan nyeri (skala 1 - 3) yang dideskriptifkan dismenore ringan. Dapat diartikan bahwa kompres hangat dapat menurunkan nyeri dismenore, responden sebagian besar mengalami penurunan 2 skala nyeri. Penurunan nyeri responden ini karena kompres hangat dapat memberikan rasa hangat kepada responden untuk mengurangi nyeri, penurunan nyeri terjadi karena adanya perpindahan panas secara konduksi dari buli-buli yang diletakkan di perut bagian bawah ke dalam perut yang melancarkan peredaran darah, menurunkan ketegangan otot dan membuat nyaman/rileks pada responden.

Setelah diberikan kompres hangat remaja putri mendeskripsikan nyerinya berkurang dan merasa nyaman. Intervensi kompres hangat yang diberikan ini mampu mengurangi nyeri responden menjadi nyeri ringan (skala 1 - 3) sampai sedang sehingga mereka dapat melanjutkan aktivitas seharihari.Fakta dilapangan dari 17 responden yang mengalami dismenore dengan skala nyeri 4-6 setelah dilakukan kompres hangat seluruh responden mengatakan ada penurunan nyeri. Pemberian kompres hangat dilakukan dengan perlakuan yang sama dan sesuai prosedur dengan menggunakan buli-buli dan air panas, perpindahan panas akibat paparan langsung dari buli-buli ke perut bagian bawah.

Sesuai yang disampaikan oleh (Kozier \& Erb's, 2009), bahwa penggunaan kompres air hangat membuat sirkulasi dan vaskularisasi darah lancar, dengan cara menggunakan bulibuli panas yang di bungkus dengan kantong. Cara pemindahannya secara konduksi dimana terjadi pemindahan panas dari buli-buli ke dalam perut bagian bawah sehingga terjadi vasodilatasi yang membuat relaksasi pada otot. Kompres air hangat dengan suhu $42-50,5^{\circ} \mathrm{C}$ mengakibatkan terjadinya vasodilatasi di daerah simphisis pubis yang bisa membuka aliran darah membuat sirkulasi darah lancar kembali sehingga terjadi relaksasi pada otot mengakibatkan kontraksi otot menurun dan nyeri berkurang.

Hasil penelitian sesuai dengan penelitian yang dilakukan oleh Wahyuningsih (2013) yang menyatakan bahwa dari 30 responden di STIKES RS Baptis Kediri, sesudah diberikan kompres air hangat 19 responden $(63,3 \%)$ mengalami intensitas nyeri ringan dan 11 responden $(36,7 \%)$ nyeri sedang. Penelitian yang dilakukan oleh Rohmawaty dan Ekawati (2014) juga menyatakan sebagian besar responden setelah diberikan kompres air hangat mengalami nyeri ringan sebanyak 19 responden $(55,9 \%)$ responden dan sebanyak 12 responden $(35,3 \%)$ mengalami nyeri sedang.

\section{Intensitas Nyeri Sebelum diberi Kompres Air Dingin}

Hasil penelitian menunjukkan bahwa intensitas nyeri sebelum diberi kompres air dingin rata-rata 5,06, intensitas nyeri terendah 4 dan intensitas nyeri tertinggi 6. Selain 
Hasil penelitian sesuai dengan penelitian yang dilakukan oleh Indriyani (2012) yang menyatakan ada pengaruh kompres hangat terhadap penurunan nyeri haid dengan nilai significant sig. $(0,00<0,05)$. Penelitian yang dilakukan oleh Murtiningsih (2015) yang menyatakan terdapat perbedaan tingkat nyeri dismenore sebelum dan sesudah kompres hangat pada remaja.

\section{Perbedaan Intensitas Nyeri Sebelum dan Sesudah diberi Kompres Air Dingin}

Hasil penelitian menunjukkan bahwa ada perbedaan intensitas nyeri sebelum dan sesudah diberi kompres air dingin pada remaja putri dengan dismenore dengan $\mathrm{p}$ value 0,000 . Hal ini menunjukkan bahwa terjadi penurunan intensitas nyeri sesudah diberikan kompres air dingin.

Sesuai dengan teori menurut Chapman (2006) tujuan dalam penanganan nyeri adalah mengurangi rasa nyeri sebesar mungkin dengan efek samping yang paling kecil. Hasil penelitian menunjukkan bahwa semua responden mengalami penurunan nyeri sesudah diberikan kompres air dingin dengan intensitas nyeri yang berbeda-beda antara $3-5$. Hal ini terjadi menurut Franser (2009) karena kompres dingin dapat mengurangi aliran darah ke suatu bagian dan mengurangi perdarahan serta edema. Diperkirakan bahwa terapi dingin menimbulkan efek analgetik dengan memperlambat kecepatan hantaran saraf sehingga impuls nyeri yang mencapai otak lebih sedikit. Mekanisme lain yang mungkin bekerja adalah bahwa persepsi dingin menjadi dominan dan mengurangi persepsi nyeri.

Hasil penelitian ini sejalan dengan penelitian Kartika (2008) tentang pengaruh kompres dingin terhadap penurunan intensitas nyeri bendungan payudara pada ibu post partum. Hasil penelitiannya menunjukkan bahwa bahwa ada pengaruh pemberian kompres dingin terhadap penurunan intensitas nyeri pada bendungan payudara pada ibu post partum.

\section{Efektivitas Kompres Air Hangat dan Kompres Air Dingin terhadap Penurunan Intensitas Nyeri pada Remaja Putri dengan Dismenore}

Hasil penelitian rata-rata intensitas nyeri pada kelompok kompres air hangat mengalami penurunan. Hal ini sesuai dengan penelitian Astuti (2011) tentang efektivitas pemberian kompres hangat terhadap kejadian dismenore pada remaja. Hasil akhir menunjukkan adanya penurunan nyeri setelah pemberian kompes hangat dengan ( $p$-value $=$ $0,000)$. Hal ini diperkuat oleh Perry dan Potter (2005) yang mengatakan bahwa panas dari bulibuli akan berpindah ke dalam tubuh sehingga menyebabkan pelebaran pembuluh darah yang dapat mengurangi spasme otot sehingga kontraksi menurun dan nyeri yang dirasakan akan berkurang.

Tidak hanya kompres hangat saja, tetapi kelompok kompres dingin juga mengalami penurunan yang sangat signifikan. Pernyataan ini sesuai dengan penelitian Khodijah (2011) yang melakukan penelitian tentang efektivitas kompres dingin terhadap penurunan intensitas nyeri pasien fraktur. Hasil akhir menunjukan bahwa responden mengalami penurunan nyeri dengan (pvalue $=0,000$ ). Hal ini dikarenakan dingin memiliki efek analgetik dan anestesi lokal dalam mengurangi intensitas nyeri yang dirasakan seseorang.

Berdasarkan hasil penelitian ini juga dapat dilihat perbandingan keefektifitasan dari kedua perlakuan terhadap intensitas nyeri pada penderita dismenorea. Uji statistik untuk mengetahui perbandingan tersebut dengan menggunakan uji Mann-Whitney. Berdasarkan hasil uji tersebut diketahui ada perbandingan perubahan rata-rata intensitas nyeri antara kompres hangat dan kompres dingin. Rata-rata selisih perubahan intensitas nyeri pada kelompok kompres air hangat sebesar 2,65 dan kompres air dingin sebesar 1,41, dapat dilihat perubahan rata-rata intensitas nyeri pada kelompok kompres air hangat lebih efektif menurunkan dismenorea.

Perbedaan yang terjadi karena kompres air hangat memberikan efek berupa meningkatkan aliran darah ke bagian tubuh yang mengalami nyeri sehingga dapat menyingkirkan produk-produk inflamasi seperti bradikinin, histamin, dan prostaglandin yang akan menimbulkan rasa nyeri lokal (Anugraheni dan Wahyuningsih, 2013).

Berdasarkan hasil penelitian kompres dingin mempunyai pengaruh terhadap penurunan intensitas nyeri pada remaja putri dengan dismenore di MAN Kendal setelah pemberian kompres air dingin. Hal ini ditunjukkan dengan hasil penelitian bahwa terjadi penurunan nilai rata-rata skala nyeri 
setelah pemberian intervensi kompres air dingin 1,41 .

Hasil dari rata-rata penurunan skala nyeri dari kedua intervensi menunjukkan bahwa kompres hangat lebih efektif dalam menurunkan nyeri pada remaja putri dengan dismenore.

\section{KESIMPULAN DAN SARAN}

Berdasarkan hasil penelitian dapat disimpulkan bahwa intensitas nyeri sebelum diberi kompres air hangat rata-rata 4,94, dan sesudah rata-rata 2,29. Terdapat perbedaan intensitas nyeri sebelum dan sesudah diberi kompres air hangat pada remaja putri dengan dismenore ( $\mathrm{p}$ value $0.000<0.05)$. Intensitas nyeri sebelum diberi kompres air dingin ratarata 5,06, dan sesudah rata-rata 3,65 , terdapat perbedaan intensitas nyeri sebelum dan sesudah diberi kompres air dingin pada remaja putri dengan dismenore ( $\mathrm{p}$ value $0.000<0.05)$. Kompres air hangat lebih efektif dalam menurunkan intensitas nyeri daripada kompres air dingin pada remaja putri dengan dismenore.

Bagi remaja putri yang mengalami dismenore dapat menggunakan terapi kompres air hangat atau kompres air dingin secara mandiri saat mengalami nyeri dismenore sehingga dapat mengurangi konsumsi obatobatan penghilang rasa nyeri.

\section{DAFTAR PUSTAKA}

Anugraheni dan Wahyuningsih. (2013). Efektifitas Kompres Hangat Dalam Menurunkan Intensitas Nyeri Dysmenorrhoea Pada Mahasiswi Stikes RS. Baptis Kediri. Jurnal STIKES Volume 6, No. 1, Tahun Juli 2013.

Arofah, N. I. (2010). Dasar-dasar Fisioterapi pada Cedera Olahraga.http://ryrilumoet. blogspot.com Diakses pada tanggal 22 Oktober 2016.

Astuti, A. M. (2011). Efektivitas pemberian kompres hangat terhadap kejadian dismenore pada remaja.Fakultas kedokteran Universitas Muhamadiyah Jakarta.Diperoleh tanggal 11 Maret 2017 dari http://psik8 umj.ac.id/library/ index.php?p=show_detail\&I d=1306.

Bobak. (2005). Keperawatan maternitas. Jakarta: EGC.

Chapman V. (2006). Asuhan Kebidanan Persalinan dan Kelahiran. Jakarta: EGC.

Dinas Kesehatan Kabupaten Kendal. (2015).
Profil Kesehatan Kabupaten Kendal. Kendal: DKK Kendal.

Dinas Kesehatan Provinsi Jawa Tengah. (2015). Profil Kesehatan Jawa Tengah. Semarang: Dinas Kesehatan Provinsi Jawa Tengah.

Fraser, Diane M. (2009). Myles. Buku Ajar Bidan. Jakarta: Buku Kedokteran EGC.

Harry. (2007). Mekanisme Endhorphin Dalam Tubuh tersedia pada http//klikharry. files.wordpress.com. (Diperoleh 11 Maret 2017).

Indriyani, Y.D. (2012). Pengaruh Kompres Hangat Terhadap Nyeri Haid pada Remaja Putri di Dusun Kebonhui dan Dusun Pangkalan Desa Margajaya Kecamatan Tanjungsari Kabupaten Sumedang. Jurnal Bhakti Kencana Medika, Volume 2, No. 4, September 2012.

Info Sehat. (2008). Faktor-Faktor yang mempengaruhi disminore. From :http://iqvita.wordpress.com/2010/05/ 08/ faktor-faktor- yangmempengaruhikejadian-disminore/, diunduh pada tanggal 15 Oktober 2016.

Kartika, A. W. (2008). Pengaruh kompres dingin terhadap penurunan intensitas nyeri bendungan payudara pada ibu post partum di wilayah kerja puskesmas kecamatan gending kabupaten probolinggo. Tugas Akhir, Program Studi Ilmu Keperawatan, Fakultas Kedokteran. Universitas Brawijaya Malang.Diperoleh 11 Maret 2017 darihttp://elibrary.ub.ac.id/handle/123456 789/18021.

Katzung, B.G. (2006). Basic \& Clinical Pharmacology. 10th ed. New York : McGraw-Hill Companies.

Khodijah, S. (2011). Efektifitas Kompres Dingin Terhadap Penurunan Intensitas Nyeri Pasien Fraktur Di Rindu B RSUP H. Adam Malik Medan. (online). (http://repository.usu.ac.id/bitstream/Abs tra ct.pdf, diakses 22 Oktober 2016).

Kozier B dan Gleniora Erb. (2009). Buku Ajar Praktik Keperawatan Klinis edisi ke-5. Jakarta: EGC.

Lowdermilk. (2010). Maternity nursing $8^{\text {th }}$ edition. Canada: Mosby.

Laila NN. (2013). Buku Pintar Menstruasi. Yogyakarta: Buku Biru.

Misaroh dan Proverawati. (2009). Menarch. 
Yogyakarta: Nuha Medika.

Murtiningsih, L.K. (2015). Penurunan Nyeri Dismenore Primer Melalui Kompres Hangat pada Remaja. Jurnal Keperawatan Volume 3 Nomor 2 Agustus 2015.

Muttaqin, A. (2011). Buku ajar asuhan keperawatan klien dengan gangguan system persyarafan. Jakarta: Salemba Medika.

Ningsih. (2011). Efektivitas Paket Pereda Terhadap Intensitas Nyeri Pada Remaja Dengan Dismenore di SMAN Kecamatan Curup.Tersedia http://lontar.ui.ac.id.(Diperoleh Oktober 2016).

Oktaviana, A., \& Imron, R. (2012). Menurunkan Nyeri Dismenorea Dengan Kompres Hangat. Jurnal Keperawatan, 8 (2), 137-141.

Potter dan Perry, (2005). Fundamental Keperawatan Konsep, Proses dan Praktik. Jakarta: EGC.

Price, A. Sylvia., \& Wilson, M. L (2005).Patofisiologi : konsep klinis, proses-proses penyakit. Edisi 6, Volume II. Jakarta : EGC.

Rizqi, Z. K. H. D. (2012). Efektivitas stimulasi kulit dengan kompres hangat dan kompres dingin terhadap penurunan persepsi nyeri kala I fase aktif persalinan fisiologis.di peroleh tanggal 29 Oktober 2013. Dari http://www.e-jurnal. com/2013/11/efektifitas-stimulasi-kulitdengan.html.

Rohmawaty, S dan Ekawati, H. (2014), Perbedaan Pemberian Kompres Hangat Dan Aromatherapy Terhadap Penurunan Nyeri Menstruasi (Dismenore) Pada Siswi Kelas XI SMA Negeri 1 Karangbinangun. Jurnal surya, Vol.01, No. XVII, Maret 2014.

Tamsuri. (2007). Konsep dan penatalaksanaan nyeri. Jakarta: EGC.

Uliyah, M. dan Hidayat, M. (2008). Keterampilan Dasar Praktik Klinik untuk Kebidanan. Jakarta: Salemba Medika.

Wilmana, P.F., dan Gan, S.G. (2007). Analgesik-Antipiretik Analgesik AntiInflamasi Nonsteroid dan Obat Gangguan Sendi Lainnya. Dalam: Gan, S.G., Editor. Farmakologi dan Terapi. Edisi 5. Jakarta: Gaya Baru. 